\title{
A Nonsense Mutation in the FMO3 Gene Underlies Fishy Off-Flavor in Cow's Milk
}

\author{
Anne Lundén, Stefan Marklund, Victoria Gustafsson, and Leif Andersson ${ }^{1}$ \\ Department of Animal Breeding and Genetics, Swedish University of Agricultural Sciences, Uppsala, Sweden
}

\begin{abstract}
Fish-odor syndrome or Trimethylaminuria (OMIM \#602079) in humans is an inborn error of metabolism associated with a characteristic fishy body odor due to elevated levels of trimethylamine (TMA) in body fluids. It is caused by loss-of-function mutations in FMO3 encoding flavin-containing mono-oxygenase 3. A fishy off-flavor is occasionally observed in cow's milk and it has been established recently that this phenotype is due to elevated TMA levels. Here, we report that fishy off-flavor in cow's milk is caused by a nonsense mutation (R238X) in the bovine FMO3 ortholog. RT-PCR analysis indicated that the mutant transcript is present in a very low amount. The mutation was found to be surprisingly common $(q=0.155)$ in one breed of cattle.
\end{abstract}

[The sequence data described in this paper have been submitted to GenBank with accession nos. AF488417-AF488422. The following individuals kindly provided reagents, samples, or unpublished information as indicated in the paper: K. Sandberg and I. Hansson.]

Fishy off-flavor in milk is characterized by a distinct, unpleasant taste and smell, reminiscent of rotting fish. Problems with fishy off-flavor in milk have been reported in the Swedish Red and White dairy breed (SRB), and a recent study documented that this quality defect is due to elevated levels of trimethylamine (TMA; Lundén et al. 2002). Exact figures on the current prevalence of fishy odor among Swedish dairy cows are difficult to estimate, as no routine organoleptic testing on milk from individual cows is performed. However, when random samples of bulk milk from individual farms were judged to have a fishy off-flavor, tests on samples from individual cows within the herd showed that the off-flavor most often originates from one or a few cows (Lundén et al. 2002). The offflavor was shown to be recurrent in the affected cows, regardless of the dietary measures taken to reduce the problem. To what extent this off-flavor occurs in other countries is not known, as the vast majority does not perform regular tests for off-flavor in bulk milk at the farm level.

Fish-odor syndrome or Trimethylaminuria is an autosomal recessive disorder in humans characterized by abnormal secretion of TMA in breath, urine, sweat, saliva, and vaginal secretions (OMIM \#602079, http://www.ncbi.nlm.nih.gov). The TMA is derived from the intestinal degradation of food/ feed components rich in TMA or its precursors. Under normal conditions, the TMA produced is oxidized to the odor- and tasteless compound TMA-oxide by the liver enzyme flavincontaining mono-oxygenase (FMO; Hlavica and Kehl 1977). The TMA oxide is thereafter excreted in the urine (Al-Waiz et al. 1987). The fishy odor is a consequence of impaired oxidation of TMA (Spellacy et al. 1980). The fish-odor syndrome in humans is due to loss-of-function mutations in FMO3 encoding an isoform of flavin-containing mono-oxygenase (Dolphin et al. 1997; Treacy et al. 1998; Akerman et al. 1999; Basarab et al. 1999; Forrest et al. 2001).

In this study, we show that fishy off-flavor in cow's milk is caused by a nonsense mutation in the FMO3 gene.

'Corresponding author.

E-MAIL Leif.Andersson@bmc.uu.se; FAX 46-18-4714833.

Article and publication are at http://www.genome.org/cgi/doi/10.1101/ gr.240202. Article published online before print in November 2002.

\section{RESULTS}

\section{Bovine FMO3 Sequences}

Bovine FMO3 sequences corresponding to human FMO3 exons $3,6,7,9$, and intron 8 were generated and the sequences have been deposited in GenBank (AF488417-AF488421). Subsequently, the complete coding region of the bovine FMO3 gene was sequenced from RT-PCR products from liver mRNA (GenBank AF488422). The exonic sequences generated from genomic DNA showed 100\% identity to the cDNA sequence obtained from the RT-PCR products, and the FMO3 specificity was strongly supported by the high-sequence similarity to other mammalian FMO3 sequences. For example, a Blast comparison between the complete coding FMO3 sequence obtained here and the corresponding human sequence (GenBank NM_006894) showed 85\% and 82\% identity at the nucleotide and amino acid levels, respectively.

\section{Identification of an FMO3 Nonsense Mutation}

Partial cattle FMO3 sequences obtained from a cow producing milk with strong fishy off-flavor and a control cow producing normal milk were compared. The compared sequences included altogether $1522 \mathrm{bp}$, and $808 \mathrm{bp}$ of these represent mRNA sequence. The coding part includes 268 codons, corresponding to $\sim 50 \%$ of the protein. The only sequence difference found between the two cows was a C/T nucleotide substitution located at position 62 in exon 6 (Fig. 1). The $\mathrm{C} \rightarrow \mathrm{T}$ substitution changes the codon for arginine (R) at position 238 to a stop codon (X); the numbering of amino acid positions is based on the human amino acid sequence given in GenBank NM_006894. This nonsense mutation is thus denoted R238X. The pyrosequencing test confirmed that the affected cow was homozygous for the R238X substitution, whereas the control cow was homozygous $\mathrm{R} / \mathrm{R}$ at residue 238 (Fig. 1). The PCR reaction also amplified a product of very similar length originating from another member of the FMO family (most likely the bovine ortholog of the human dJ127D3.2 gene with GenBank accession no. AL021026), which made it difficult to use the TaqI RFLP for genotyping the R238X mutation. However, the pyrosequencing test was 
(A)

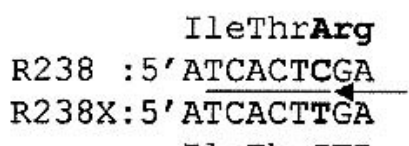

(B)

\section{IleThrSTP}
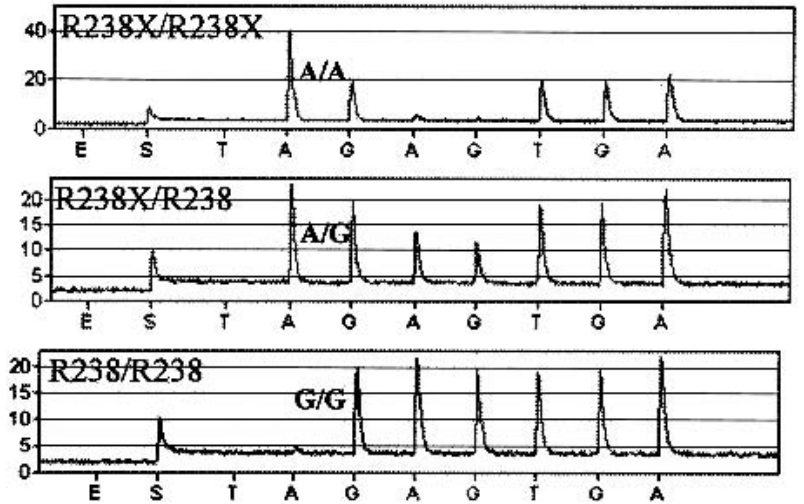

Figure 1 (A) Alignment of codon 236-238 for the normal (R238) and mutant (R238X) FMO3 allele in cattle. This region was analyzed using pyrosequencing. The location of the sequencing primer and the six positions sequenced are indicated. (B) Pyrosequencing results from the three different genotypes at codon 238 . The sequenced reverse strand has the sequence (A/G)AGTGA, in which the $A / G$ polymorphism corresponds to the R238X nonsense mutation.

not affected by this coamplification due to the additional FMO3 specificity imposed by the internal sequencing primer.

\section{The R238X Substitution Is Closely Associated With the Presence of Fishy Off-Flavor in Cow's Milk}

The pyrosequencing test was used to test a case-control material comprising cows producing milk classified as having a fishy off-flavor and controls from the same herds (Table 1). A Class 2 score means that two trained persons both classified the sample as having a strong fishy off-flavor, whereas Class 1

Table 1. $F M O 3$ Genotype Distributions in a Group of 21 Swedish Red and White Cows With or Without Fishy Off-flavor in Milk and in Animals Representing the Four Dairy Breeds in Sweden

\begin{tabular}{|c|c|c|c|c|}
\hline & \multicolumn{4}{|c|}{ FMO3 genotype at codon 238} \\
\hline & $R / R$ & $R / X$ & $x / X$ & Total \\
\hline \multicolumn{5}{|l|}{ Case/control study } \\
\hline \multicolumn{5}{|l|}{ Sensory evaluation: ${ }^{\mathrm{a}}$} \\
\hline Normal & 5 & 0 & 0 & 5 \\
\hline Class 1 & 3 & 3 & 1 & 7 \\
\hline Class 2 & 0 & 1 & 8 & 9 \\
\hline \multicolumn{5}{|l|}{$\begin{array}{l}\text { Population study } \\
\text { Breed: }\end{array}$} \\
\hline Swedish Red and White & 71 & 27 & 2 & 100 \\
\hline Swedish Holstein & 100 & 0 & 0 & 100 \\
\hline Swedish Polled & 25 & 0 & 0 & 25 \\
\hline Swedish Jersey & 23 & 0 & 0 & 23 \\
\hline
\end{tabular}

implies that the two persons judged the fishy off-flavor as strong/moderate, moderate/moderate, or moderate/normal. The results revealed a very strong association between the FMO3 R238X nonsense mutation and strong fishy off-flavor, as eight of nine animals with the Class 2 score were homozygous for this mutation and the ninth was heterozygous. In contrast, the five control samples were homozygous normal. The Class 1 group contained animals of all three genotype classes.

\section{The R238X Substitution Occurs at a Surprisingly High Frequency in the Swedish Red and White Breed} The population screening involved 248 animals representing the four dairy breeds in Sweden. The R238X substitution was not found in Swedish Holstein, Swedish Polled, or Swedish Jersey, but was surprisingly common in the Swedish Red and White breed (Table 1). A total of 2 homozygous mutant and 27 heterozygotes were observed among 100 animals, giving an allele frequency estimate for the mutation as high as $15.5 \%$.

\section{RT-PCR Analysis of a Heterozygous R238X Carrier and a Homozygous Normal Animal}

Only the wild-type transcript appeared well represented in the mRNA sample from the R238X carrier. Only a very weak sequencing signal could be observed from the mutant transcript, at least 10 times weaker than the one from the wildtype transcript. A similar result was obtained using liver mRNA from a second heterozygous R238X carrier. Consequently, we could not use the mRNA to search for possible additional mutations present in the FMO3 allele associated with fishy off-flavor. However, the RT-PCR experiment confirmed that the R238X mutation occurs in an expressed FMO3 gene.

The comparison of the full-length cDNA sequence from the wild-type alleles from one carrier and one homozygous normal individual revealed three single nucleotide polymorphisms (SNPs). Two of these were silent substitutions (T1067C and $\mathrm{A} 1085 \mathrm{C})$, whereas the third (A877G) was a missense substitution $(\mathrm{E} 287 \mathrm{G})$. These are expected to be true SNPs and not sequence differences between FMO paralogs. In the RT-PCR experiments, we found no indication of coamplification of an FMO paralog as we did for the 147-bp PCR product used for genotyping (see above).

\section{DISCUSSION}

The present study provides compelling evidence for the observed FMO3 nonsense mutation R238X causing fishy offflavor in milk. This conclusion is based on (1) the identification of an obvious loss-of-function mutation in a gene associated with a similar syndrome in humans, (2) a very strong association between the presence of this mutation and a strong fishy off-flavor in a case/control material, and (3) the presence of this mutation in the only breed (SRB) tested with well-documented cases of a fishy off-flavor in milk.

The $\mathrm{R} 238 \mathrm{X}$ mutation causes a premature termination, eliminating $>50 \%$ of the FMO3 enzyme that is expected to comprise 532 amino acids as in the human FMO3 protein. Similar nonsense mutations in humans (E305X, E314X) have been shown to lead to a complete loss of enzyme activity (Treacy et al. 1998; Akerman et al. 1999). Moreover, we ob- 
served only barely detectable levels of the mutant transcript in liver mRNA from two heterozygous carriers of R238X. This is most probably explained by nonsense-mediated mRNA decay (NMD; Culbertson 1999). It is very likely that cows homozygous for the R238X mutation show a complete lack of FMO3 activity necessary for the oxidation of TMA to an odorless compound. This provides a plausible explanation for the fishy off-flavor of the milk from these cows. Milk samples from five of the cows homozygous for the mutation and included in this study have been analyzed previously for TMA content by use of dynamic headspace gas chromatography (Lundén et al. 2002). The results showed that these milk samples all had comparatively high concentrations of TMA, whereas the milk from normal cows showed nondetectable or, in a few cases, very low TMA concentrations.

The results suggested a recessive mode of inheritance for the fishy off-flavor in cow's milk in agreement with the recessive inheritance of the fishy-odor syndrome in humans. However, there was not a perfect agreement between this model and the observations from the case/control study, as one carrier was scored as having strong fishy off-flavor (Class 2) and one homozygous mutant showed a moderate off-flavor (Class 1). We think there are two potential explanations for this deviation from a strict recessive model. The fishy offflavor is influenced by environmental factors such as the presence of TMA precursors or FMO inhibitors in the feed. For example, the TMA concentration in the milk from one of the homozygous mutants was shown to vary between 1 and 16 mg TMA $/ \mathrm{kg}$ milk within a single lactation (A. Lundén, M. Imhof, R. Gauch, and J.-O. Bosset, unpubl.). The results also suggested that heterozygous carriers of the R238X mutation under some environmental conditions may produce fishy offflavored milk due to haploinsufficiency. Secondly, the sensory evaluation is a somewhat subjective measure. The test panel consisting of two trained persons goes through a considerable number of milk samples during one day and may have some difficulties in discerning the various off-flavors present in the milk samples and also in discriminating between different flavors.

In the present material, the mutation was only observed among the SRB animals, but at a relatively high frequency. This is in complete accordance with the experiences made by the staff at the milk-analysis laboratory that performed the sensory analysis, who have so far only encountered the fishy off-flavor in milk from SRB cows. We analyzed the pedigree data for all carriers and homozygous mutants, but we did not find a single common ancestor of these animals within the last 10 generations. The results suggest that the mutation has been existing in the SRB population for a relatively long period of time. The origin of the mutation probably dates back at least to the beginning of the last century, judging from the available pedigree information on affected animals (data not shown). Moreover, the pedigree data indicate that the mutation may exist in cattle populations of Ayrshire origin in other countries as well.

To the best of our knowledge, this is the first identified gene that has a profound influence on the perceived quality of raw milk. The genotyping method described in this study can now be used by the breeding industry to eliminate the problem in those breeds in which the FMO3 nonsense mutation is present. A practical way to reduce the problem would be to genotype currently used breeding bulls and young potential breeding bulls before progeny testing, thereby eliminating carriers from breeding.

\section{METHODS}

\section{Cattle Samples and DNA Preparation}

The present study included two different groups of dairy cattle. The first material comprised 21 cows of the Swedish Red and White breed (SRB) with information from sensory analyses on the milk. Ten of the cows belonged to either of the two experimental herds, Jälla and Kungsängen at the Swedish University of Agricultural Sciences in Uppsala. The remaining cows belonged to either of four commercial herds, all of which had received complaints about fishy off-flavor in the bulk milk. In three of the six herds, control cows were chosen that were comparable with the affected cows as regards breed, lactation number, and stage of lactation, but were producing milk with a normal taste and smell.

A population study was performed in which bulls and cows from the four dairy breeds in Sweden were genotyped for the observed FMO3 nonsense mutation. From each of the two major breeds, SRB and Swedish Holstein, 100 individuals were chosen, whereas from the two smaller breeds, Swedish Polled and Swedish Jersey, 25 and 23 individuals were sampled, respectively. Genomic DNA was prepared from blood samples according to standard protocols.

\section{PCR Amplification and Sequencing of FMO3 From Genomic DNA Samples}

Exonic parts of the FMO3 gene were amplified from genomic DNA samples using primers corresponding to sequences well conserved between the human, rabbit, mouse, and rat FMO3 sequences available in GenBank (Table 2). Two genomic DNA samples were used, one from a cow that had been shown to repeatedly produce milk with a fishy flavor and the other from a control cow producing normal milk.

The PCR was performed in $10-\mu \mathrm{L}$ reactions including $1 \times$ PCR buffer, $1.5 \mathrm{mM} \mathrm{MgCl}_{2}, 0.2 \mathrm{mM}$ of each dNTP, 2.5 pmole of each primer, $25 \mathrm{ng}$ genomic DNA, and $0.35 \mathrm{U}$ AmpliTaq DNA polymerase (PerkinElmer). Thermocycling was carried out in a PTC200 machine (M.J. Research) and included 40 cycles with annealing at $53^{\circ} \mathrm{C}$ for 30 sec and extension at $72^{\circ} \mathrm{C}$ for $2 \mathrm{~min}$. The denaturation step was at $95^{\circ} \mathrm{C}$ for $1-2 \mathrm{~min}$ in the first two cycles, and $94^{\circ} \mathrm{C}$ for $30 \mathrm{sec}$ in the remaining cycles. The products were analyzed by agarose gel electrophoresis (4\% Nusieve/Seakem 3:1, FMC Bioproducts). The PCR products were sequenced directly with BigDye terminators and an ABI377 instrument (PerkinElmer). Sequence analysis and comparison of sequences was done using the Sequencher software (GENE CODES).

\begin{tabular}{|c|c|}
\hline $\begin{array}{l}\text { FMO3 region } \\
\text { amplified }^{\mathrm{a}}\end{array}$ & $\begin{array}{l}\text { Forward }(F) \text { and reverse }(R) \\
\text { primer sequences } 5^{\prime}-3^{\prime}\end{array}$ \\
\hline exon 3 & $\begin{array}{l}\text { F: GACCATGCAGAAGAGGGCAG } \\
\text { R: CTTAAACTGTATGTATTTCAGGAGGTT }\end{array}$ \\
\hline exon 6 & $\begin{array}{l}\text { F: CATCATCAGCTCCAGAAGTGG } \\
\text { R: TAAAGGCATCAAGCCATAGTT }\end{array}$ \\
\hline exon 7 & $\begin{array}{l}\text { F: CAGAATCCTGAGGAAAGAGCC } \\
\text { R: ATTACTTGTCCTGCCCAGCG }\end{array}$ \\
\hline exon 8-9 & $\begin{array}{l}\text { F: GATGAATGATATTAATGAGAAAATGG } \\
\text { R: CCGGTCCCACTGGGTCAG }\end{array}$ \\
\hline
\end{tabular}

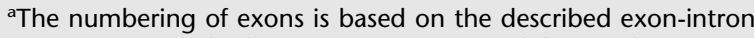
organization for the human FMO3 gene (Dolphin et al. 1997). 


\section{Genotyping of the FMO3 R238X Nonsense Mutation}

The SNP in exon 6 was genotyped by pyrosequencing (Ronaghi et al. 1998) using a Luc96 instrument (Pyrosequencing $\mathrm{AB})$. This included PCR amplification of a 147-bp product from genomic DNA samples using the forward primer $5^{\prime}$ biotin-GATGAAGGCTATCCATGGGAC and the reverse primer 5'-TAAAGGCATCAAGCCGTAGTTCTC. The PCR was performed in $20-\mu \mathrm{L}$ reactions with concentrations of reagents as above. Thermocycling was carried out in a PE9600 instrument (PerkinElmer) and included an initial denaturation step at $94^{\circ} \mathrm{C}$ for $2 \mathrm{~min}$, followed by 5 cycles at $94^{\circ} \mathrm{C}$ for $30 \mathrm{sec}, 55^{\circ} \mathrm{C}$ for $30 \mathrm{sec}, 72^{\circ} \mathrm{C}$ for $45 \mathrm{sec}, 43 \mathrm{cycles}$ at $94^{\circ} \mathrm{C}$ for $20 \mathrm{sec}, 50^{\circ} \mathrm{C}$ for $30 \mathrm{sec}, 72^{\circ} \mathrm{C}$ for $45 \mathrm{sec}$, and a final extension step at $72^{\circ} \mathrm{C}$ for $5 \mathrm{~min}$. Pyrosequencing on the forward strand was done using the reverse sequencing primer 5'-TGAGGAAT GTTTCAAATC and conditions according to the manufacturer's recommendations.

\section{RT-PCR Amplification and Sequencing of FMO3 cDNA}

Ten livers from SRB cattle were collected, and the pyrosequencing test showed that two were heterozygous carriers of the R238X mutation. One of these livers, as well as one liver from a homozygous wild-type cow were used for mRNA preparation, RT-PCR amplification, and direct sequencing of the coding FMO3 region. Two additional primers were used for this purpose, designed from sequences in the untranslated regions that showed conservation between other mammalian FMO3 sequences. Thus, the 5'UTR primer 5'-GGACTT AGACACACAGAAGAAAAGAAG and the 3'UTR primer 5'GAGGTGTGAAATTCTTATTTTTTAAATAG were used in pairs with the reverse and forward pyrosequencing PCR primers, respectively. Thus, the coding sequence was amplified in two overlapping pieces, each including the site of the R238X mutation. Poly(A) mRNA was isolated from liver and RT-PCR was carried out using the Quickprep Micro mRNA Purification Kit and the First-Strand cDNA Synthesis Kit, respectively (Amersham Pharmacia Biotech). The reverse transcription was done using 200 ng mRNA and random hexamer priming in a 15$\mu \mathrm{L}$ reaction volume. A total of $2 \mu \mathrm{L}$ of the completed first strand reaction were used in each PCR reaction, with a total volume of $12 \mu \mathrm{L}$, so that the final concentrations of dNTP, $\mathrm{Mg}^{2+}$, primers, and AmpliTaq polymerase were the same as above. The thermocycling conditions were as described above for sequencing genomic DNA amplicons, but the $5^{\prime}$ part of the cDNA required a repeated PCR to yield enough product for sequencing.

\section{ACKNOWLEDGMENTS}

Laila Ericsson at the Milk analysis laboratory, Bollnäs, is acknowledged for her skill in identifying various off-flavors in milk. Dr. Kaj Sandberg kindly provided DNA samples for the population screening, and Dr. Ingemar Hansson helped us to collect tissue samples for RT-PCR analysis. We thank Linda Tjäder, Oskar Hansson, and Ulla Gustafsson for technical assistance. The study was funded by The Swedish Research Council for Environment, Agricultural Sciences and Spatial Planning.

The publication costs of this article were defrayed in part by payment of page charges. This article must therefore be hereby marked "advertisement" in accordance with 18 USC section 1734 solely to indicate this fact.

\section{REFERENCES}

Akerman, B.R., Forrest, S., Chow, L., Youil, R., Knight, M., and Treacy, E.P. 1999. Two novel mutations of the FMO3 gene in a proband with trimethylaminuria. Hum. Mut. 13: 376-379.

Al-Waiz, M., Mitchell, S.C., Idle, J.R., and Smith, R.L. 1987. The metabolism of ${ }^{14} \mathrm{C}$-labelled trimethylamine and its $N$-oxide in man. Xenobiotica 17: 551-558.

Basarab, T., Ashton, G.H., Menagé, H.P., and McGrath, J.A. 1999. Sequence variations in the flavin-containing mono-oxygenase 3 gene (FMO3) in fish odour syndrome. Brit. J. Dermatol. 140: $164-167$.

Culbertson, M.R. 1999. RNA surveillance unforeseen consequences for gene expression, inherited genetic disorders and cancer. Trends Genet. 15: 74-80.

Dolphin, C.T., Janmohamed, A., Smith, R.L., Shepard, E.A., and Phillips, I.R. 1997. Missense mutation in flavin-containing monooxygenase 3 gene, FMO3, underlies fish-odour syndrome. Nat. Genet. 17: 491-494.

Forrest, S.M., Knight, M., Akerman, B.R., Cashman, J.R., and Treacy, E.P. 2001. A novel deletion in the flavin-containing monooxygenase gene (FMO3) in a Greek patient with trimethylaminuria. Pharmacogenetics 11: 169-174.

Hlavica, P. and Kehl, M. 1977. Studies on the mechanism of hepatic microsomal $N$-oxide formation, the role of cytochrome P-450 and mixed function amine oxidase in the $\mathrm{N}$-oxidation of N,N-dimethylamine. Biochem. J. 164: 487-496.

Lundén, A., Gustafsson, V, Imhof, M., Gauch, R., and Bosset, J.O. 2002. High trimethylamine concentration in milk from cows on standard diets is expressed as fishy off-flavour. J. Dairy Res. 69: 383-390.

Ronaghi, M., Uhlén, M., and Nyrén, P. 1998. A sequencing method based on real-time pyrophosphate. Science 281: 363, 365 .

Spellacy, E., Watts, R.W.E., and Goolamali, S.K. 1980. Trimethylaminuria. J. Inherit. Metab. Dis. 2: 85-88.

Treacy, E.P., Akerman, B.R., Chow, L.M.L., Youil, R., Bibeau, C., Lin, J., Bruce, A.G., Knight, M., Danks, D.M., Cashman, J.R., et al. 1998. Mutations of the flavin-containing mono-oxygenase gene (FMO3) cause trimethylaminuria, a defect in detoxication. Hum. Mol. Genet. 7: 839-845.

\section{WEB SITE REFERENCE}

http://www.ncbi.nlm.nih.gov; National Center for Biotechnology Information (NCBI).

Received March 6, 2002; accepted in revised form September 10, 2002. 


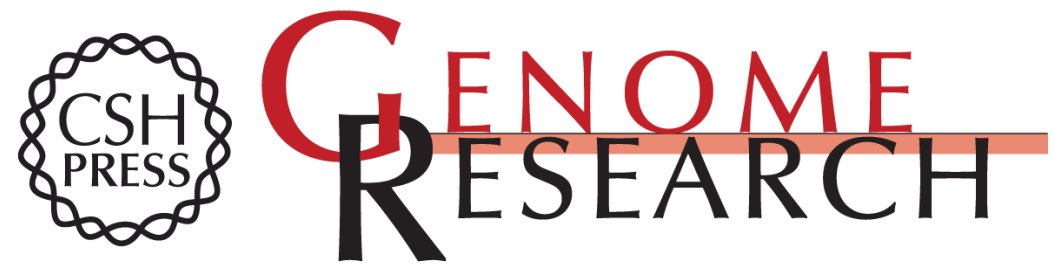

\section{A Nonsense Mutation in the FMO3 Gene Underlies Fishy Off-Flavor in Cow's Milk}

Anne Lundén, Stefan Marklund, Victoria Gustafsson, et al.

Genome Res. 2002 12: 1885-1888

Access the most recent version at doi:10.1101/gr.240202

References This article cites 11 articles, 2 of which can be accessed free at:

http://genome.cshlp.org/content/12/12/1885.full.html\#ref-list-1

\section{License}

Email Alerting Receive free email alerts when new articles cite this article - sign up in the box at the Service top right corner of the article or click here.

\section{Affordable, Accurate Sequencing.}

To subscribe to Genome Research go to: https://genome.cshlp.org/subscriptions 